Article

\title{
Assessment of the Impact of Geomagnetic Disturbances on Korean Electric Power Systems
}

\author{
Byoung-Soo Joo ${ }^{1}$, Jung-Wook Woo ${ }^{1}$, Jeong-Hun Lee ${ }^{1}$, Injoo Jeong ${ }^{2}$, Jungmin Ha ${ }^{2}$, Se-Hee Lee ${ }^{2}$ \\ and Soobae Kim ${ }^{2, *}$ \\ 1 Korea Electric Power Research Institute (KEPRI), Korea Electric Power Corporation (KEPCO), Daejeon 34056, \\ Korea; soony.joo@kepco.co.kr (B.-S.J.); mark.woo@kepco.co.kr (J.-W.W.); jhlee923@kepco.co.kr (J.-H.L.) \\ 2 Electrical Engineering Department, Kyungpook National University, Daegu 41566, Korea; \\ jij1142@knu.ac.kr (I.J.); gkwjdals10@knu.ac.kr (J.H.); shlees@knu.ac.kr (S.-H.L.) \\ * Correspondence: soobae.kim@knu.ac.kr; Tel.: +82-53-950-7218
}

Received: 11 June 2018; Accepted: 17 July 2018; Published: 23 July 2018

\begin{abstract}
Geomagnetic disturbances have the potential to impact the operation of electric power systems, and thus the assessment of their impacts is required as the first step for secure power system operations. While the effects of the disturbances have been observed primarily at higher latitudes, geomagnetic problems are also observed at mid and low latitude locations, in particular including neighboring countries to Korea such as China and Japan. This paper deals with the assessment of impact of geomagnetic disturbances on Korean electric power systems. For the assessment, the geoelectric fields induced by the geomagnetic disturbances are calculated using geomagnetic data measured over the past 20 years in order to quantify the strength of geomagnetic events in Korea. Then, the geomagnetic currents on the grid driven by the geoelectric fields are computed. Finally, the increased reactive power absorption in high voltage transformers is analyzed and accordingly the change of system voltage magnitudes is identified to evaluate whether the system maintains the voltage stability. The systematic study concludes that during a strong geomagnetic disturbance, the Korean electric power system satisfies the associated standards in the U.S. and maintains system stability.
\end{abstract}

Keywords: geomagnetic disturbances; transformer half-cycle saturation; geoelectric field; geomagnetic induced currents; reactive absorption; system voltage levels; Korean electric power system

\section{Introduction}

It has been a growing concern that geomagnetic disturbances (GMDs) have the potential to impact on the operation of electric power systems [1-3]. GMDs occur when particles discharged from the sun during solar storms cause intensive variation in the Earth's magnetic field. Through Faraday's law of induction, the changing magnetic field creates the geoelectric field at Earth's surface and in the ground, which in turn generates geomagnetically induced currents (GIC) to flow along transmission lines and through transformer neutral-groundings. When these quasi-direct current (DC) GIC currents, typically in the order of $0.1 \mathrm{~Hz}$ to $0.001 \mathrm{~Hz}$, flow into a transformer winding, the operating point is shifted and the transformer cores become saturated. This is known as half-cycle saturation. As a consequence, the transformer suffers hot spot heating, produces harmonics, and absorbs more reactive power losses.

Many problems and even blackouts of power systems due to GIC have been reported in [4-6]. The most well-known example in North America is the collapse of the Hydro-Quebec system with the occurrence of $1.7 \mathrm{~V} / \mathrm{km}$ geoelectric field in March 1989. More than six million people remained without power for nine hours. Another representative GIC event, also referred to as the Halloween 
storm, caused a blackout in the south of Sweden at the end of October 2003. About 50,000 customers were left without electricity during the blackout that lasted for about an hour.

Two primary risks to the bulk power system from GMDs are noted by the North American Electric Reliability Council (NERC) [4]. The first one is the potential damage of bulk power system assets, typically associated with the high voltage transformers. The second is the loss of reactive power support, which may lead to voltage instability and power system collapse. The potential impacts of GMDs, in particular focusing on the voltage instability, can be assessed with following three steps: (1) calculation of the geoelectric field; (2) computation of GIC over the network; and (3) calculation of reactive power losses in transformers and evaluation of voltage collapse.

NERC TPL-007-1 standard (Transmission system planned performance for geomagnetic disturbance events) has been approved in September 2016 in order to ensure safe and reliable operation of the interconnected power systems from GMDs. All the electric power utilities in the U.S. are required to assess the vulnerability of their transmission systems to GMDs. If the results of the vulnerability assessment do not satisfy the requirements, corrective actions should be developed to mitigate their impacts and to manage system reliability. More details about the standard, including procedures, requirements and implementation timeline can be found in [7].

It was commonly understood that the effects of GIC are primarily experienced in higher geomagnetic latitude regions such as North America and North Europe. However, recent work has established that GIC problems are also observed at low and equatorially locations. While these locations are exposed to the greatly reduced intensity, the disturbances can persist for very long periods of time [8]. For example, the loss of 14 large $400 \mathrm{kV}$ transformers have been reported in South Africa during the 2003 geomagnetic storm over 29-31 October [9]. Furthermore, power systems in southern Japan and China neighboring to Korea experienced widespread GIC flows [10-12]. No accidents associated with GMDs have been reported in Korea. However, considering these circumstances, the importance of the vulnerability assessment of Korean power systems to GMDs has been increasing.

In this paper, Korean electric power grids have been studied with the presence of GMD. The assessment has been completed following the NERC TPL-007-1 standard. For the assessment, the geoelectric field is calculated using measured geomagnetic data in order to quantify the strength of geomagnetic events in the past 20 years. Then, GIC flows are analyzed by developing the DC equivalent circuit of Korean power systems. The amounts of increased reactive power absorption in high voltage transformers are evaluated, and the change of system voltages is then identified by incorporating the additional reactive power demands into alternating current (AC) power flow analysis.

This paper is organized as follows. Section 2 presents a brief analytic basis to model the GICs and assess the effects. In Section 3, the calculation of geoelectric fields using measured geomagnetic data is presented. Section 4 illustrates the evaluation of GMD impact on the Korean electrical power grid, including the computation of increased reactive power losses in all transformers, and the change in voltage levels. Finally, the conclusion is made in Section 5.

\section{Procedure of Assessing the GMD Impact}

This section describes the theoretical basis used to model GICs and the risk assessment procedure for GMD impacts on power systems.

\subsection{Calculation of Induced Geoelectric Field}

There are a number of methods used to calculate the induced geoelectric fields from the variation of geomagnetic fields [13]. These methods differ from simplifications of the complex phenomena in that the currents in the ionosphere or magnetosphere are functions of time and space, and the earth's conductivity distribution is required. The simplest and the most appropriate method is to use the plane wave theory requiring magnetic field measurements and one-dimensional (1-D) layered earth conductivity model. Equations (1) and (2) show the relationship between the geomagnetic field, earth surface impedance, and the geoelectric field. 


$$
\begin{gathered}
E_{x}(\omega)=Z(\omega) H_{y}(w) \\
E_{y}(\omega)=-Z(\omega) H_{x}(w)
\end{gathered}
$$

where $E_{x}(\omega)$ : Northward geoelectric field $(\mathrm{V} / \mathrm{m}) ; E_{y}(\omega)$ : Eastward geoelectric field $(\mathrm{V} / \mathrm{m}) ; H_{x}(\omega)$ : Northward geomagnetic field intensity $(\mathrm{A} / \mathrm{m}) ; H_{y}(\omega)$ : Eastward geomagnetic field intensity $(\mathrm{A} / \mathrm{m})$; $Z(\omega)$ : Earth surface impedance $(\Omega)$.

As shown in (1) and (2), the electric fields can be calculated with frequency domain techniques. Time series of magnetic data are transformed into the frequency domain using a fast Fourier transform (FFT) and multiplied with the function of Earth's surface impedance. Then the result is converted to the time series of electric filed values by the use of the inverse FFT.

The earth surface impedance depends on the earth conductivity structure below the power system. The conductivity $(\sigma)$ is varied with depth $(d)$, represented with a 1-D layered, laterally uniform model as shown in Figure 1.

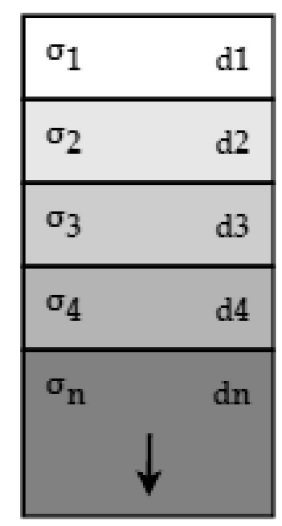

Figure 1. One-dimensional (1-D) layered earth conductivity model reproduced with permission from [4], NERC, 2012.

The earth surface impedance can be obtained with following Equations (3)-(6) [14].

$$
\begin{gathered}
k_{n}=\sqrt{j \omega \mu_{0} \sigma} \\
r_{n}=\frac{1-k_{n} \frac{Z_{n+1}}{j \omega \mu_{0}}}{1+k_{n} \frac{Z_{n+1}}{j \omega \mu_{0}}} \\
Z_{n}=j \omega \mu_{0} \frac{1-r_{n} e^{-2 k_{n} d_{n}}}{k_{n}\left(1-r_{n} e^{-2 k_{n} d_{n}}\right)}
\end{gathered}
$$

For the bottom layer, the surface impedance is:

$$
Z_{n}=\frac{j \omega \mu_{0}}{k_{n}}
$$

where: $\omega$ : Angular frequency $(\mathrm{rad} / \mathrm{s}) ; \mu_{0}$ : Permeability of free space; $\sigma_{n}$ : Conductivity of layer $n$ $(1 / \Omega \cdot \mathrm{m}) ; r_{n}$ : Thickness of layer $n(\mathrm{~m})$.

\subsection{Calculation of GIC}

The presence of geoelectric field on a power grid is equivalent to modeling a set of voltage source in the transmission lines. The value of voltage magnitude is the integral of the electric field along the line shown in Equation (7): 


$$
V_{A B}=\int_{A}^{B} \vec{E} \cdot \overrightarrow{d l}
$$

Assuming the geoelectric fields are uniform over the power system network, Equation (7) can be simplified to (8) with the path independence of the integral:

$$
V_{A B}=L_{A B}\left(E_{x} \sin \theta+E_{y} \cos \theta\right)
$$

where $L_{A B}$ is the distance between the nodes $A$ and $B$, and $\theta$ is the angle between the line connecting the nodes and the $y$-axis.

Because GIC flows have much lower frequency than $1 \mathrm{~Hz}$, a DC treatment is reasonable. Thus, the GIC calculation can be done by reducing the AC power network to its DC equivalent. GIC flows are then determined by solving the DC network equation shown in (9):

$$
\bar{I}=\bar{G} V
$$

where $\bar{G}$ is a symmetric matrix with real conductance values, and the voltage vector, $\bar{V}$.

\subsection{Calculation of Reactive Power Losses}

Once the GIC flows have been calculated, transformer reactive power losses associated with the GICs are determined. These reactive power losses vary linearly with terminal voltage and the amount of the GIC, and also depend on transformer configuration affecting $K_{r}$ in (10) [15]. The losses are represented with (10) [16].

$$
Q_{G I C, r}=K_{r} V_{p u, r} I_{G I C, r}
$$

where $Q_{G I C, r}$ is the GIC-related reactive power loss for the transformer $\mathrm{r}$ in Mvar, $K_{r}$ is a transformer specific constant with Mvars/amp, $V_{p u, r}$ is the per unit AC terminal voltage for the transformer, and $I_{G I C, r}$ is the-per phase GIC through neutral in transformer $r$.

\section{Calculation of the Electric Field Using Measured Data}

\subsection{Magnetometer Data Acquisition}

In Korea, since 1996, magnetometer data have been collected at four observatories including Icheon, Jeju, Gangneung, and Yongin. These data have been provided online by Korea Space Weather Center [17]. The magnetic fields were recorded with a $1 \mathrm{~min}$ resolution on average. These time series data are used to calculate the geoelectric field.

\subsection{1-D-Layered Earth Conductivity Model in Korea}

For the geoelectric field calculation, the required subsurface information was obtained from [18], where 1-D conductivity structure in the Korean peninsula was presented using the magnetotelluric method. [18] examined the conductivity with depth at seven different locations and minor differences exist among the conductivity value. For simplification of the study, the averaged value of each layer was used. In addition, the geoelectric field computation requires data with depths of hundreds of kilometers because of the quasi-DC nature of the field [4]. However, only four layers with depths of up to $100 \mathrm{~km}$ were revealed in [18]. For the additional information, the IP-4 model in [19] has been added, and the developed 1-D layered conductivity model is presented in Table 1. 
Table 1. Developed 1-D layered earth conductivity model in Korea for the geoelectric field calculation.

\begin{tabular}{ccc}
\hline Layer Number $(i)$ & Depth $\left(d_{i}\right)(\mathbf{k m})$ & Conductivity $\left(\sigma_{i}\right)(\mathbf{1} / \Omega \cdot \mathbf{m})$ \\
\hline 1 & 0.43 & $1 / 1152$ \\
2 & 16.6 & $1 / 12660$ \\
3 & 87.96 & $1 / 1077$ \\
4 & 150 & $1 / 209$ \\
5 & 160 & $1 / 50$ \\
6 & 110 & $1 / 20$ \\
7 & 150 & $1 / 5.62$ \\
8 & 230 & $1 / 1.58$ \\
\hline
\end{tabular}

\subsection{Result of Calculated Geoelectric Field}

The method to calculate the geoelectric field with the magnetometer data was implemented using Matlab. Figure 2 shows the calculated geoelectric fields, Ex (Northward) and Ey (Eastward) with the data at the Icheon observatory on 19 October 2003. The abrupt change of the magnetic fields, nearly $50 \mathrm{nT}$ in $B x$ and $60 \mathrm{nT}$ in $B y$ led to the sudden increase of the geoelectric fields, $157 \mathrm{mV} / \mathrm{km}$ in $E x$ and $121 \mathrm{mV} / \mathrm{km}$ in Ey. Geoelectric fields at four stations in the years from 1996 to 2016 were also obtained. Much missing data existed in the magnetometer data, and some data that looked incorrect were not included in the calculation. The maximum of $E x$ and $E y$ during a day over the past twenty years was presented in Figure 3. The largest amplitude of the geoelectric field was $107.9 \mathrm{mV} / \mathrm{km}$ of $E x$ and $591.4 \mathrm{mV} / \mathrm{km}$ of $E y$ at the Icheon station on 24 December 2001.
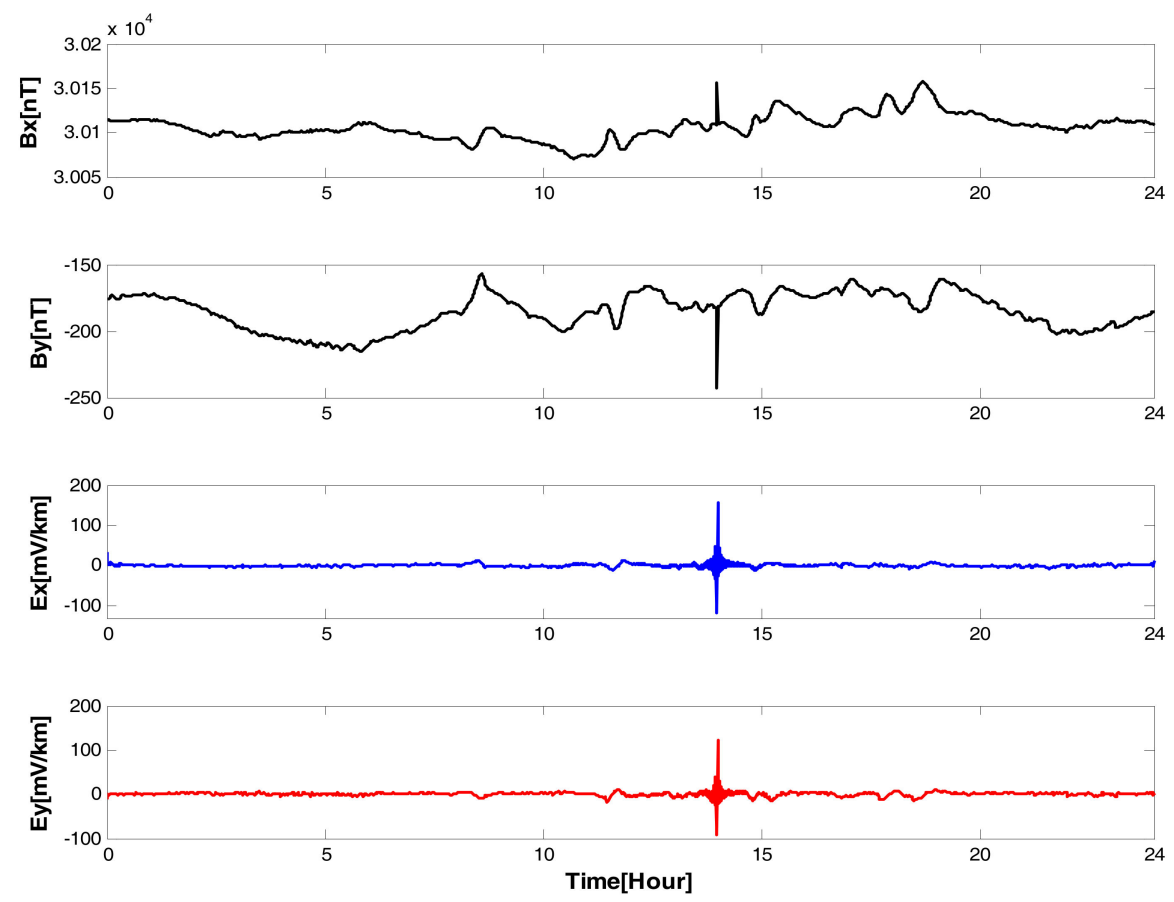

Figure 2. Calculated geoelectric fields on 19 October 2003 at the Icheon observatory. 


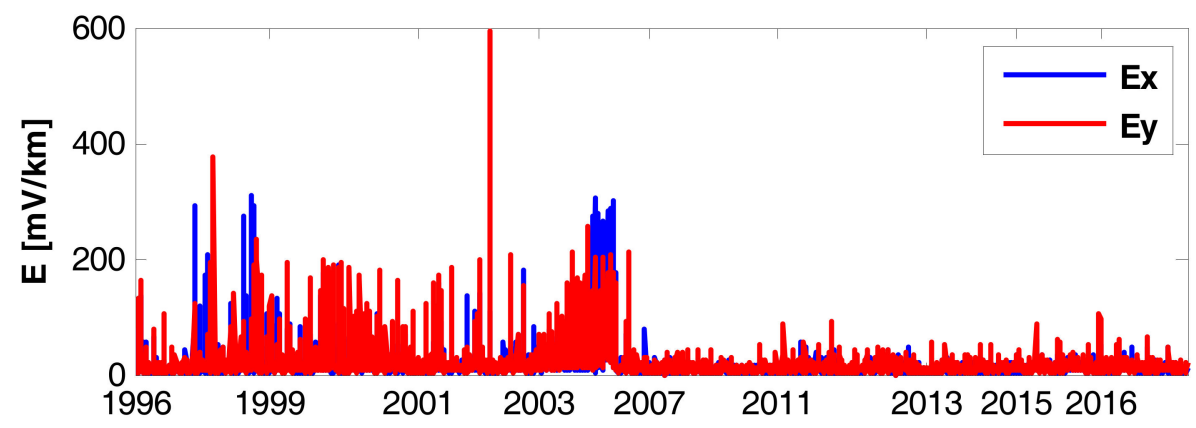

(a) Icheon

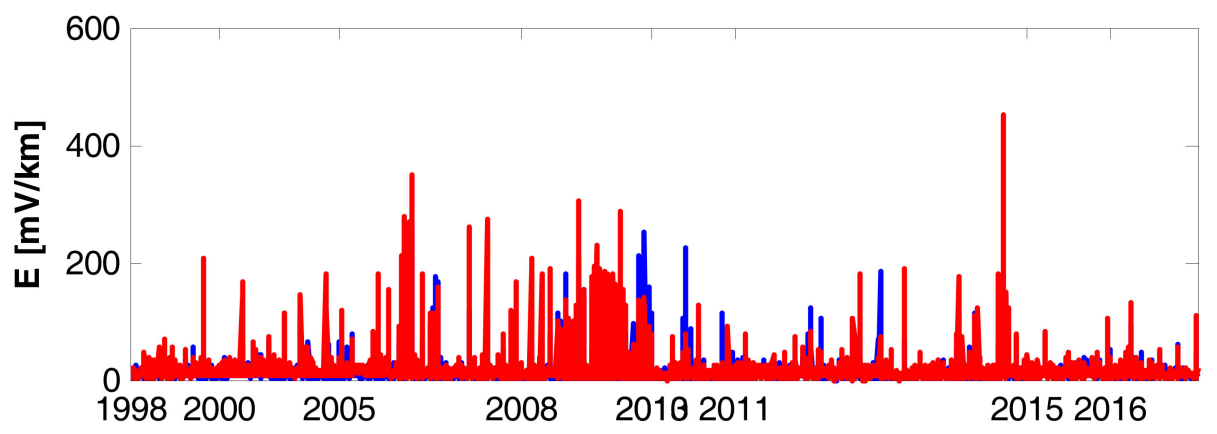

(b) Jeju

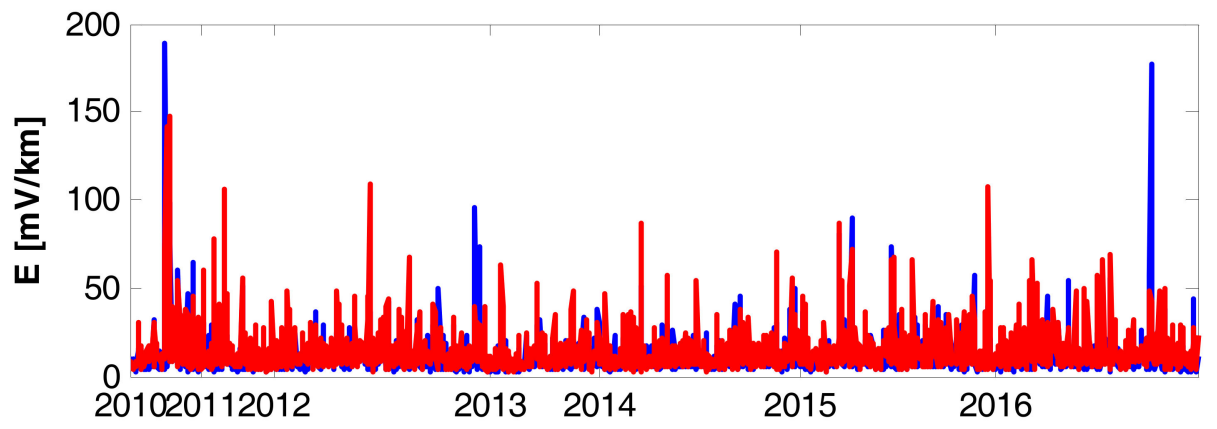

(c) Gangneung

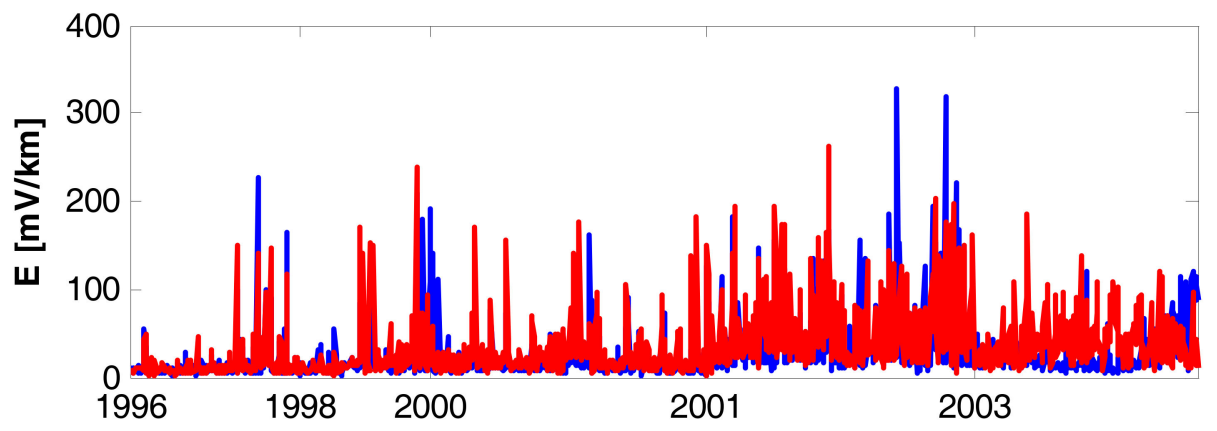

(d) Yongin

Figure 3. Daily maximum of geoelectric field (Ex: Blue, Ey: Red).

\section{Assessment of GMD Impact on Korean Power Systems}

\subsection{NERC TPL-007 Vulnerability Assessment}

NERC vulnerability assessment is based on a benchmark GMD event, on which the maximum geoelectric field strength of $8 \mathrm{~V} / \mathrm{km}$ is defined at a reference location (geomagnetic latitude of 60 degrees). The benchmark case is associated with the most severe GMD event, which occurred once 
every 100 years. A new draft of TPL-007-1 expected to be approved includes the local enhancement of the geoelectric field amplitude of up to $12 \mathrm{~V} / \mathrm{km}$. The intensity of GMD varies depending on latitude-based geomagnetic location, and thus the scaling factor is allowed in TPL-007. Table 2 presents the geomagnetic scaling factor. In addition, TPL-007 requires the preparation of a corrective action plan in order to mitigate the effect of GMD on power systems if the maximum transformer GIC is over 75 A per phase with the benchmark event.

Table 2. Geomagnetic field scaling factors [20].

\begin{tabular}{cc}
\hline Geomagnetic Latitude (Degrees) & Scaling Factor \\
\hline$\leq 40$ & 0.1 \\
45 & 0.2 \\
50 & 0.3 \\
57 & 0.7 \\
59 & 0.9 \\
$\geq 60$ & 1 \\
\hline
\end{tabular}

\subsection{Simulation with Korean Power Systems}

The assessment was made with a practical Korean power system representing the peak loading in 2016. Overall system information is presented in Table 3. As presented in Section 3.3, the most severe GMD that happened in Korea during the past 20 years might generate a geoelectric field amplitude of about $0.6 \mathrm{~V} / \mathrm{km}$. In this vulnerability study, a $12 \mathrm{~V} / \mathrm{km}$ strength with consideration of the latitude scaling was applied uniformly over the entire Korean power system. Geomagnetic latitude in South Korea is less than 30 degrees, and thus the geomagnetic scaling $(0.1)$ was multiplied by the benchmark amplitude of $12 \mathrm{~V} / \mathrm{km}$, effectively $1.2 \mathrm{~V} / \mathrm{km}$.

Table 3. Information of the Korean power system for study.

\begin{tabular}{cccc}
\hline Type & Numbers & MW & Mvar \\
\hline Generators & 411 & $83,652.2$ & $19,450.1$ \\
Loads & 1328 & $82,427.7$ & $27,572.7$ \\
Switched Shunts & 573 & 0 & $15,091.3$ \\
Buses & 2250 & - & - \\
Transformers & 687 & - & - \\
Branches & 2329 & - & - \\
\hline
\end{tabular}

The assessment was performed with the PowerWorld simulator providing the calculation of GIC flows over the network and additional reactive power losses in transformers [21]. The PowerWorld simulator also offers analysis on how the system voltages are changed with the additional reactive power demands caused by GIC flows.

To create a DC equivalent circuit required for GIC calculation, geographic location information including latitude and longitude at all system buses and substations were entered into the simulator. One ohm of substation grounding resistance is assumed according to the substation design criterion at Korea Electric Power Corporation. All the transformer neutral resistances were ignored and accordingly, the larger GICs are expected. Associated with $\mathrm{Kr}$ coefficient, transformer classification was made on the basis that $765 \mathrm{kV}$ and $345 \mathrm{kV}$ is single-phase (three separate cores) and the autotransformer and $154 \mathrm{kV}$ is with a 3-phase, 5-legged transformer.

With the geoelectric field amplitude $(1.2 \mathrm{~V} / \mathrm{km})$ and a northern direction (0 degree), GIC flows were analyzed in terms of DC voltage and DC current on transmission lines, and transformer neutral currents and its reactive power losses. The induced DC voltages on transmission lines are presented in Figure 4. Various levels of DC voltages appeared because of their dependence on the length as well as on the placement of a transmission line. The largest DC voltage in absolute value was $111.85 \mathrm{~V}$ on 
$93.36 \mathrm{~km}$ transmission line, making angles of 183.33 degrees with respect to the northern direction. Figure 5 shows the GIC amp per phase in absolute value on transmission lines. A maximum value of 185.58 A was found. GIC neutral currents of transformers are shown in Figure 6. The maximum GIC neutral current per phase flowed through one of the generator step up (GSU) transformers at a nuclear power plant, of which the value was $51.13 \mathrm{~A}$. It should be noted that this GIC amplitude was smaller than $75 \mathrm{~A}$, the allowable maximum value of the NERC guideline. The additional reactive power demands of transformers were also investigated. The largest reactive losses were identified with a $765 \mathrm{kV}$ transformer and its value was 37.16 Mvar.

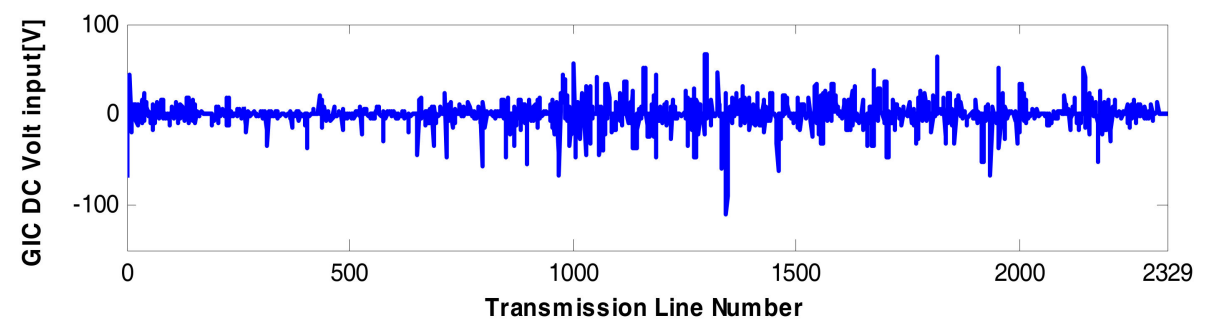

Figure 4. Geomagnetically induced currents (GIC) direct current (DC) volts on the Transmission Line.

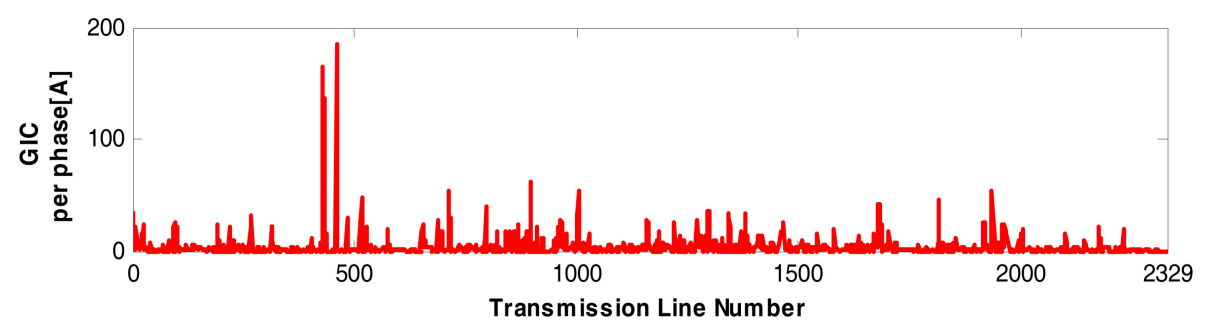

Figure 5. GIC per phase (in absolute value) on the Transmission Line.

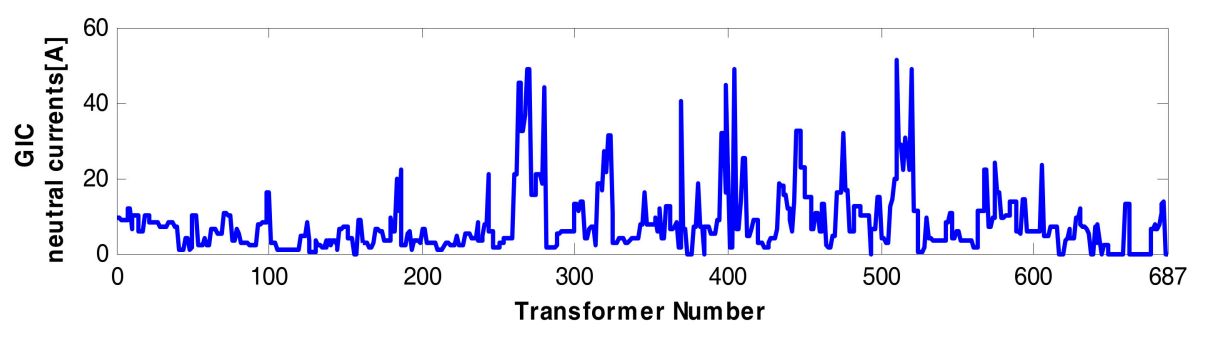

Figure 6. Transformer neutral currents (in absolute value).

Total sum of reactive losses absorbed at all the system transformers is given in Table 4. Maximum and minimum values were obtained by considering the variation of the geoelectric field direction. The amount of maximum losses was 1145.5 Mvar when the geoeletric field had an orientation of 114 degrees. The minimum value was $883.6 \mathrm{Mvar}$ with a direction of 26 degrees. For the purpose of comparison, when the amplitude of geoelectric field was increased to $6 \mathrm{~V} / \mathrm{km}$ (effectively the same as $60 \mathrm{~V} / \mathrm{km}$ at the reference location), reactive power losses are accordingly increased by about five times as shown in Table 4.

The additional reactive power consumptions lead to the change of system voltage levels. The change was analyzed, taking account both reactive power losses from the event, with 1.2 and $6 \mathrm{~V} / \mathrm{km}$ in Table 4. 
Table 4. Additional Mvar losses at transformers with $1.2 \mathrm{~V} / \mathrm{km}$ geomagnetic disturbances (GMD) in a Korean power system.

\begin{tabular}{cccc}
\hline $\begin{array}{c}\text { E-Field Direction } \\
\text { (Degrees) }\end{array}$ & $\begin{array}{c}\text { Mvar Losses } \\
\text { with 1.2 V/km }\end{array}$ & $\begin{array}{c}\text { Mvar Losses } \\
\text { with 6 V/km }\end{array}$ & Remark \\
\hline 0 & 961.4 & 4807.1 & - \\
114 & 1145.5 & 5727.4 & Maximum \\
26 & 883.6 & 4417.7 & Minimum \\
\hline
\end{tabular}

The simulation results are provided with the contour plot in Figure 7. The plot shows the difference in bus voltage magnitude between before and after the GMD impacts. The addition of reactive power losses (961.4 Mvar) resulted from the $1.2 \mathrm{~V} / \mathrm{km}$ strength led to a voltage variation between 0.023 p.u. and -0.007 p.u. As shown in the Figure 7 , the changes were very small over the system. This is because an additional 961.4 Mvar in losses are not big enough compared to the total reactive power generation of 19,450 Mvar. It was interesting to find the voltage increase, as represented with red color in the contour plot. The cause of the increase was due to switched shunt devices providing the reactive power supports to maintain a specified voltage level at the bus. The largest support was $55.04 \mathrm{Mvar}$, which increases the voltage level by 0.023 p.u. Figure 7 also shows the voltage profiles with the $6 \mathrm{~V} / \mathrm{km}$ geoelectric field. Compared to the change from $1.2 \mathrm{~V} / \mathrm{km}$ amplitude, most areas experienced a change in system voltage, especially a decrease, ranging from 0.018 p.u. to -0.015 p.u. A violent storm, with the amplitude of $60 \mathrm{~V} / \mathrm{km}$ at the reference location, would not bring about a voltage collapse in a Korean power system.

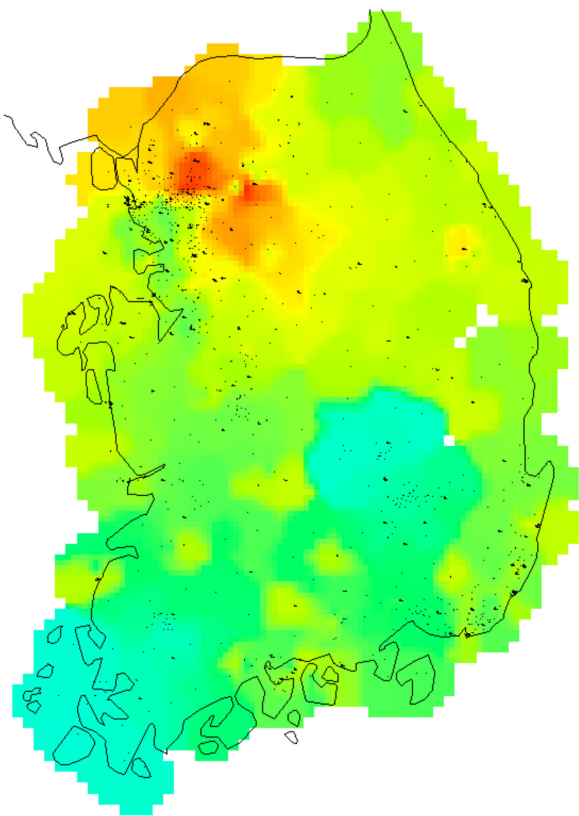

(a) with $1.2 \mathrm{~V} / \mathrm{km}$ strength

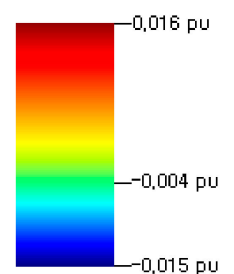

Figure 7. Contour plot of voltage differences before and after GMD.

\section{Conclusions}

The potential for GMDs to impact the operation of power systems has been a growing concern. Though representative events have occurred mostly in the higher-latitude regions, several failures have been reported at mid and lower latitude regions. Thus, careful considerations are required to monitor the GIC flows and analyze the impact on the bulk power system and if needed, mitigation plan should be prepared. This paper presents the vulnerability assessment of Korean electric power grid with the presence of GMDs. First, the amplitude of geoelectric field is calculated using the 
magnetometer data. It is identified that the largest GMD producing the geoelectric field strength of $0.6 \mathrm{~V} / \mathrm{km}$ occurred on 24 December 2001. Second, based on the benchmark event proposed by the NERC, DC voltages, and GIC currents on transmission lines, GIC neutral currents in transformers are obtained. When Korean power systems are exposed to $1.2 \mathrm{~V} / \mathrm{km}$ geoelectric field, the maximum GIC neutral is estimated to be $51.13 \mathrm{~A}$, which satisfies the NERC standard defining $75 \mathrm{~A}$ as the maximum allowable current. Reactive power losses and the change of voltage profiles are also studied. If a super-mega storm with $6 \mathrm{~V} / \mathrm{km}$ in Korea (effectively same as $60 \mathrm{~V} / \mathrm{km}$ at a reference location, latitude of 60 degrees) takes place, the Korean power system will not show big changes in voltage magnitudes and will maintain system voltage stability.

Author Contributions: Conceptualization, B.-S.J., J.-W.W. and S.K.; Methodology, I.J., J.H., J.-H.L., S.-H.L. and S.K.; Validation, B.-S.J., J.-H.L. and S.K.; Investigation, I.J., J.H. and S.-H.L.; Resources, J.-H.L. and S.-H.L.; Writing-Original Draft Preparation, B.-S.J., and S.K.; Writing-Review \& Editing, B.-S.J., S.-H.L. and S.K.; Supervision, S.-H.L., J.-W.W. and S.K.; Project Administration, B.-S.J. and S.K.; Funding Acquisition, J.-W.W. and S.K.

Funding: This research was funded by Korea Electric Power Corporation (KEPCO) (Grant number: R16TA24).

Acknowledgments: The authors gratefully acknowledge the support for this work provided by Korea Electric Power Corporation (KEPCO), Naju, Korea and Korea Electric Power Research Institute (KEPRI), Daejeon, Korea.

Conflicts of Interest: The authors declare no conflict of interest.

\section{References}

1. Pirjola, R. Geomagnetically induced currents during magnetic storms. IEEE Trans. Plasma Sci. 2000, 28, 1867-1873. [CrossRef]

2. Kappenman, J.G. Geomagnetic Storms and Their Impact on Power Systems. IEEE Power Eng. Rev. 1996, 16. [CrossRef]

3. Kappernman, J.G.; Albertson, V.D. Bracing for the geomagnetic storms. IEEE Spectr. 1990, 27, $27-33$. [CrossRef]

4. North American Electric Reliability Corporation (NERC). 2012 Special Reliability Assessment Interim Report: Effects of Geomagnetic Disturbances on the Bulk Power System. 2012. Available online: https:/ / www.ferc.com/ (accessed on 23 July 2018).

5. North American Electric Reliability Corporation (NERC). NERC Report, 13 March 1989 Geomagnetic Disturbances. Available online: https://www.nerc.com/ (accessed on 23 July 2018).

6. Pulkkinen, A.; Lindahl, S.; Viljanen, A.; Pirjola, R. Geomagnetic storm of 29-31 October 2003: Geomagnetically induced currents and their relation to problems in the Swedish high-voltage power transmission system. Space Weather 2005, 3. [CrossRef]

7. North American Electric Reliability Corporation (NERC). TPL-007-1-Transmission System Planned Performance for Geomagnetic Disturbance Events. 2016. Available online: https://www.nerc.com/ (accessed on 23 July 2018).

8. Kappenman, J. Geomagnetic Storms and Their Impacts on the U.S. Power Grid; Metatech Corporation: Goleta, CA, USA, 2010.

9. Gaunt, C.T.; Coetzee, G. Transformer failures in regions incorrectly considered to have low GIC-risk. IEEE Lausanne Power Tech. 2007. [CrossRef]

10. Liu, L.G.; Wu, W.L.; Zheng, K. Preliminary estimate of GIC risk in China's future power grid due to geomagnetic disturbance. In Proceedings of the IEEE Power and Energy Society General Meeting, Vancouver, BC, Canada, 21-25 July 2013; pp. 1-4.

11. Liu, C.M.; Liu, L.G.; Pirjola, R. Geomagnetically induced currents in the high voltage power grid in China. IEEE Trans. Power Deliv. 2009, 24, 2368-2374. [CrossRef]

12. Watari, S.; Kunitake, M.; Hori, K.T.; Kikuchi, T.; Shiokawa, K. Measurements of geomagnetically induced current in a power grid in Hokkaido, Japan. Space Weather 2009, 7. [CrossRef]

13. Marti, L.; Rezaei-Zare, A.; Boteler, D. Calculation of induced electric field during a geomagnetic storm using recursive convolution. IEEE Trans. Power Deliv. 2014, 29, 802-807. [CrossRef] 
14. North American Electric Reliability Corporation (NERC). Application Guide: Computing Geomagnetically-Induced Current in the Bulk-Power System; North American Electric Reliability Copporation: Atlanta, GA, USA, 2013.

15. Marti, L.; Berge, J.; Varma, R.K. Determination of geomagnetically induced current flow in a transformer from reactive power absorption. IEEE Trans. Power Del. 2013, 28, 1280-1288. [CrossRef]

16. Overbye, T.J.; Shetye, K.S.; Hutchins, T.R.; Qiu, Q.; Weber, J.D. Power grid sensitivity analysis of geomagnetically induced currents. IEEE Trans. Power Syst. 2013, 28, 4821-4828. [CrossRef]

17. Korea Space Weather Center. Available online: http:/ / www.spaceweather.go.kr (accessed on 23 July 2018).

18. Yang, J.; Lee, H.; Lee, C.; Kwon, B. 1-D Deep Resistivity Structure of the Korean Peninsula Using Magnetotelluric (MT) Data. J. Korean Earth Sci. Soc. 2009, 30, 153-164. (In Korean) [CrossRef]

19. Electric Power Research Institute (EPRI). One-Dimensional Earth Resistivity Models for Selected Areas of Continental United States and Alaska; Electric Power Research Institute: Palo Alto, CA, USA, 2012.

20. North American Electric Reliability Corporation (NERC). Supplemental Geomagnetic Disturbance Event Description; North American Electric Reliability Corporation: Atlanta, GA, USA, 2017.

21. Powerworld Corporation. Available online: http://www.powerworld.com/ (accessed on 23 July 2018).

(C) 2018 by the authors. Licensee MDPI, Basel, Switzerland. This article is an open access article distributed under the terms and conditions of the Creative Commons Attribution (CC BY) license (http:/ / creativecommons.org/licenses/by/4.0/). 